\title{
artigo
}

Pinheiro, V. A., Mendonça, E. M., Costa, E. C., Calisto, G. C. O., Rodrigues, J. A. R., Lima, B. A. P.

Redução de danos e políticas sobre drogas no Brasil: retrocessos e avanços

\section{Redução de danos e políticas sobre drogas no Brasil: retrocessos e avanços}

\author{
Damage reduction and policies on drugs in Brazil: backwards and advances \\ Reducción de daños y políticas sobre drogas en Brasil: atrás y avances
}

\section{RESUMO}

OBJETIVO: o presente artigo traz reflexões a respeito das políticas sobre drogas no Brasil e suas relações contraditórias no que tange à estratégia de redução de danos, especificamente na área da saúde mental, álcool e outras drogas. MÉTODO: Os métodos utilizados foram pesquisa bibliográfica e documental, privilegiando publicações de 1990 a 2021. O período da coleta de dados se deu nos anos de 2019, 2020 e 2021, onde aconteceram as principais alterações nas leis. RESULTADO: 0 debate se dá em torno de como o viés proibicionista habitou a mesma política durante todo o tempo em que a redução de danos foi considerada uma estratégia de cuidado às pessoas que usam drogas. Entretanto, a política de drogas brasileira, ganhou novos contornos a partir do ano de 2017. CONCLUSÃO: Concluiu-se que o predomínio do proibicionismo e seu retorno à legislação dos últimos anos, legitimou oficialmente a criminalização do uso de substâncias psicoativas e consequentes retrocessos em relação ao cuidado das pessoas que usam drogas.

DESCRITORES: Políticas de Saúde; Usuários de Drogas; Redução de Danos; Assistência em Saúde Mental.

\section{ABSTRACT}

OBJECTIVE: this article brings reflections on drug policy in Brazil and their contradictory relationships regarding the harm reduction strategy, specifically in the area of mental health, alcohol and other drugs. METHOD: the methods used were bibliographic and documentary research, favoring publications from 1990 to 2021. The period of data collection took place in the years 2019, 2020 and 2021, where the main changes in laws took place. RESULT: the debate revolves around how the prohibitionist bias inhabited the same policy throughout the time that harm reduction was considered a care strategy for people who use drugs. However, the Brazilian drug policy gained new contours as of 2017. CONCLUSION: it was concluded that the predominance of prohibitionism and its return to the legislation of recent years, officially legitimized the criminalization of the use of psychoactive substances and consequent setbacks in relation to the care of people who use drugs.

DESCRIPTORS: Health Policy; Drug Users; Harm Reduction; Mental Health Assistance.

\section{RESUMEN}

OBJETIVO: Este artículo trae reflexiones a respecto de políticas sobre el uso de drogas en Brasil y sus relaciones contradictorias en lo que atañe a la estrategia de reducción de daños, específicamente en el área de salud mental, alcohol y otras drogas. MÉTODO: los métodos utilizados fueron la investigación bibliográfica y documental, favoreciendo las publicaciones desde 1990 hasta 2021. El período de recolección de datos tuvo lugar en los años 2019, 2020 y 2021, donde se produjeron los principales cambios en las leyes. RESULTADO: el debate radica en como el sesgo prohibicionista habitó la misma política durante todo el tiempo en que la reducción de daños fue considerada la principal estrategia de cuidado a las personas usuarias de drogas. Sin embargo, la política de drogas brasileña ha ganado nuevos contornos desde 2017. CONCLUSIÓN: se concluyó que el predominio del prohibicionismo y su retorno a la legislación en los últimos años legitimaron oficialmente la criminalización del uso de sustancias psicoactivas y los consiguientes retrocesos en relación con el cuidado de las personas que consumen drogas.

DESCRIPTORES: Política de Salud; Consumidores de Drogas; Reducción de Daños, Centros Comunitarios de Salud Mental

RECEBIDO EM: 12/10/2021 APROVADO EM: 30/11/2021

\section{Viviane Andrade Pinheiro}

Instituto René Rachou - Fiocruz Minas. Psicóloga.

ORCID: 0000-0002-7423-0517.

\section{Edna Mara Mendonça}

Instituto René Rachou - Fiocruz Minas. Terapeuta ocupacional. ORCID: 0000-0003-4256-1407 


\section{Elizabete Cristina Costa}

Prefeitura Municipal de Betim/MG. Psicóloga.

ORCID: 0000-0003-2502-890X.

\section{Gleibson Carlos de Oliveira Calisto}

Prefeitura Municipal de Cruzília/MG. Enfermeiro.

ORCID: 0000-0001-5823-8183.

\section{José de Arimatéia Reis Rodrigues}

Universidade Federal do Pará (UFPA). Psicólogo.

ORCID: 0000-0002-9527-5968.

\section{Bruna Andrade Pinheiro de Lima}

Instituto Suassuna de Goiânia/GO. Psicóloga.

ORCID: 0000-0002-1193-1594.

\section{INTRODUÇÃO}

0 presente artigo discorre acerca das políticas sobre drogas brasileiras e traz à luz a estratégia de redução de danos, que foi introduzida e atualmente retirada enquanto possibilidade de atenção e cuidado, apontando a continuidade da visão proibicionista, elencada na Política Nacional sobre Drogas ${ }^{1}$ como um viés de intervenção, lado a lado à redução de danos, até a retirada desta última da legislação atual ${ }^{2}$.

Tais mudanças nas políticas de drogas criam impactos importantes nas diversas políticas produtoras de vida. No caso específico da saúde mental, quando relacionada às pessoas que usam drogas, por exemplo, a nova legislação sobre drogas contraria a Lei $n^{\circ} 10.2163$, que continua em vigor e preconiza a implementação de serviços substitutivos aos hospitais psiquiátricos.

$\mathrm{O}$ artigo ainda tem como objetivo elucidar a estratégia de redução de danos como ampliação do acesso ao cuidado e vinculação com os usuários de diferentes perfis, contextos e comportamentos. Ou seja, a redução de danos como acolhimento, escuta e possibilidades do viver, estando dentro ou fora das políticas governamentais, enquanto um paradigma permanente do cuidado às pessoas que utilizam substâncias psicoativas.

O Ministério da Saúde publicou a Portaria $n^{\circ} 3.5884$ e a Nota Técnica $n^{\circ} 112$, que na prática autorizam formalmente o retorno dos hospitais psiquiátricos e a interna-
No caso específico

da saúde mental,

quando relacionada

às pessoas que

usam drogas, por

exemplo, a nova

legislação sobre

drogas contraria

a Lei no 10.2163,

que continua em

vigor e preconiza

a implementação

de serviços

substitutivos

aos hospitais

psiquiátricos ção de médio e longo prazo como foco do tratamento psiquiátrico em saúde mental, o que permite o financiamento de aparelhos de eletroconvulsoterapia e as parcerias com as comunidades terapêuticas, apontando para o retorno das práticas asilares e de segregação em saúde mental e em casos de abuso de álcool e outras drogas.

Destarte, a construção das políticas de drogas no Brasil apresentou nas últimas décadas discursos opostos e contraditórios. No momento, as opções são pelas chamadas ações de combate às drogas, baseadas na criminalização das pessoas que fazem uso de substâncias psicoativas, na repressão ao tráfico de drogas, no encarceramento, na abstinência como exigência principal para atenção à saúde, na medicalização e internação involuntária/compulsória como pilares do chamado tratamento à dependência química, termo então utilizado com frequência para caracterizar as pessoas que usam drogas, com consequente retorno do estigma social à política de drogas e de saúde mental ${ }^{2}$.

É comum se identificar condutas moralistas e autoritárias, revestidas de um cunho humanitário, carregadas de "verdades" científicas e "zelosas" pelo bem-estar e pela saúde das pessoas que dizem estar socorrendo e ajudando. Tais posicionamentos e discursos baseados em comportamentos tomados como "corretos" de pessoas "que não usam drogas" são contraditórios em função da tolerância ao consumo de medicamentos e das próprias drogas lícitas, cuja cultura hoje disseminada não dispõe de questionamen- 


\section{artigo}

Pinheiro, V. A., Mendonça, E. M., Costa, E. C., Calisto, G. C. O., Rodrigues, J. A. R., Lima, B. A. P.

Redução de danos e políticas sobre drogas no Brasil: retrocessos e avanços

tos por parte dos defensores da vertente proibicionista 5 .

$\mathrm{O}$ artigo contextualiza o momento recente, que desencadeou nesse alinhamento parcial e contraditório entre a redução de danos e a Política Nacional sobre Drogas, e destaca como essa convivência foi marcada pelo tensionamento entre o viés progressista e proibicionista, mediado por ações governamentais híbridas, que tentaram apaziguar, sem sucesso, dois campos em franca oposição, gerando ambiguidades e conflitos na esfera das práticas sociais, políticas e morais relacionadas ao uso de substâncias.

Objetiva-se então, demonstrar ao leitor que, ao que parecem, as questões relacionadas aos cuidados à vida e preservação dos direitos fundamentais garantidos não são prioridades. Tal fato se justifica a partir do momento que se perdem em caracterizações monetárias e numerárias ${ }^{2}$, e ainda em marcadores ideológicos, que em nada atendem às urgências de quem clama pelo atendimento de suas necessidades humanitárias5.

\section{MÉTODO}

A reflexão teórica em questão foi organizada e sistematizada a partir da pesquisa bibliográfica e documental, a partir da análise dos seguintes documentos: Política para Atenção Integral a Usuários de Álcool e outras Drogas6, Política Nacional sobre Drogas1, Lei n ${ }^{\circ} 11.3437$, Guia Álcool e outras Drogas8, Leis Federais e Portarias do Ministério da Saúde pertinentes, Decreto $\mathrm{n}^{\circ} 9.7619$, e a Lei ${ }^{\circ} 13.84010$, que modificou vários artigos da Lei ${ }^{\circ} 11.3437$. A pesquisa bibliográfica privilegiou a consulta a livros, artigos, dissertações, teses e capítulos de livros publicados sobre o tema. Estabeleceram-se como marco temporal as publicações entre os anos de 1990 e 2021. O período da coleta de dados se deu nos anos de 2019, 2020 e 2021, onde aconteceram as principais mudanças e alterações nas leis e que merecem discussão e novos apontamentos.

A Política para Atenção Integral a Usuários de Álcool e outras Drogas (2003) será também citada como política de drogas ou sobre drogas. A Lei no 13.343 (2006) será apontada comumente por Lei de Drogas. Os sujeitos que fazem uso de substâncias psicoativas serão chamados de pessoas que fazem uso de drogas.

\section{RESULTADOS E DISCUSSÕES}

Políticas sobre Drogas e a Rede de Atenção Psicossocial

Segundo Alves ${ }^{11}$, o consumo de substâncias psicoativas, desde as civilizações antigas, esteve sob-regulação social. A princípio, eram submetidas a normas $\mathrm{e}$ convenções socialmente compartilhadas. A partir do momento em que houve uma extrapolação do contexto de uso, fez-se necessária a intervenção reguladora do Estado. Intervenção essa que tem se concretizado mediante formulação e implementação de políticas públicas. A expansão do uso trouxe uma crescente popularização das substâncias, acompanhada pelo enfraquecimento das estratégias sócio culturais de regulação do consumo, emergindo, com isso, um conjunto de questões sociais e de saúde associadas.

Segundo Castro ${ }^{12}$, o modelo de saúde adotado nos últimos séculos, e trazido até os tempos atuais, vincula o consumo de drogas à dependência química como efeito decorrente, assim como a ideia da evolução do uso individual de drogas leves até chegar as mais pesadas. As pessoas são colocadas como pertencentes a uma cultura e uma realidade não condizentes com a "normalidade”, supondo que as drogas geram estes comportamentos antissociais, que não combinam com a vida produtiva e levam ao desenvolvimento de condutas criminosas.

Portanto, os modelos morais e impositivos adotados podem contribuir para ampliação dos processos de exclusão social das pessoas que usam drogas, especialmente das consideradas ilícitas, afastando-as dos serviços assistências, ou dificultando a construção de respostas das políticas públicas ${ }^{12}$.

Em relação as consequências negativas provocadas pela imposição proibicionista pode-se citar a relação do encarceramento

\section{Tabela 1. Indicadores do Programa de Braços Abertos - DBA}

\begin{tabular}{|c|c|c|}
\hline INDICADORES & $\begin{array}{l}\text { Número de Respon- } \\
\text { dentes }\end{array}$ & $\%$ \\
\hline $\begin{array}{l}\text { Reduziram o uso de crack } 314 \\
87,90 \%\end{array}$ & 314 & $87,9 \%$ \\
\hline $\begin{array}{l}60 \text { a } 80 \text { pedras por semana } 314 \\
12 \% \text { antes do DBA e } 1 \% \text { depois } \\
\text { do DBA }\end{array}$ & 314 & $\begin{array}{l}12 \% \text { antes do DBA e } 1 \% \\
\text { depois do DBA }\end{array}$ \\
\hline $\begin{array}{l}\text { Beneficiário por tempo de efeito } \\
\text { da droga }\end{array}$ & 361 & $\begin{array}{l}64 \% \text { "fumavam o dia todo" } \\
\text { antes do DBA e } 4 \% \text { depois } \\
\text { do DBA } \\
32 \% \text { "metade do dia" antes } \\
\text { do DBA e } 42 \% \text { depois do } \\
\text { DBA } \\
4 \% \text { "por pouco tempo" antes } \\
\text { do DBA e } 34 \% \text { depois do } \\
\text { DBA }\end{array}$ \\
\hline $\begin{array}{l}\text { Reduziram o uso de outras } \\
\text { drogas }\end{array}$ & 365 & $84,38 \%$ \\
\hline $\begin{array}{l}\text { Consumo per capita de pedras de } \\
\text { crack }\end{array}$ & 314 & $\begin{array}{l}41 \text { pedras antes do DBA e } \\
17 \text { pedras depois do DBA }\end{array}$ \\
\hline Estão em tratamento de saúde & 381 & $83,3 \%$ \\
\hline
\end{tabular}


em massa e o tipo penal tráfico de drogas. O Levantamento Nacional de Informações de Penitenciárias, no período de julho a dezembro de 2019, informa no total foram 989.263 incidências, sendo que desta totalidade, 200.853 incidências estão relacionadas a delitos de drogas (20,28\%). Nestas incidências em tipos penais de drogas, os homens representavam 183.077 casos e as mulheres os restantes 17.506 casos. As informações a respeito da população prisional, por faixa etária, demostra que jovens de 18 a 24 anos são $23,29 \%$ de toda esta população e, de 25 a 29 anos, mais $21,5 \%$; e que a somatória destas chegam a $44,44 \%$ de toda população carcerária 13 .

Já com resultados positivos em relação às intervenções em redução de danos, o Programa de Braços Abertos pode ser citado. Este Programa foi uma experiência brasileira inovadora, cujo objetivo foi promover reabilitação psicossocial de usuários de crack e outras drogas em situação de rua, imersos em um contexto de vulnerabilidade social, na cidade de São Paulo. Foi implementado em abril de 2014 como resposta ao aglomerado de usuários nas cenas de uso de drogas - denominadas de "cracolândia" ou "fluxo" - no território da Luz, no centro da capital. Apresentou como diretrizes: a atenção à saúde por meio de políticas de redução de riscos e danos, de prevenção do uso de drogas, de tratamento e de assistência social, oferta de alimentação, hospedagem e acesso a atividades ocupacionais e de renda por meio de frentes de trabalho e também de qualificação profissional. A tabela abaixo apresenta indicadores do Programa14:

O ano de 2003 é considerado o marco da construção de uma política pública de saúde para pessoas que usam drogas no Brasil. O Ministério da Saúde apresenta uma proposta de atenção, influenciada por duas grandes experiências: a Reforma Psiquiátrica e o Programa Nacional de Doenças Sexualmente transmissíveis e Aids (DST/ Aids), especificamente por meio de projetos de redução de danos ${ }^{15}$.

A Política para Atenção Integral a Usuários de Álcool e outras Drogas5 reconhece a diferença entre usuário, dependente $\mathrm{e}$ traficante de drogas. Acontece então, a ex-

O ano de 2003

é considerado

o marco da

construção de uma

política pública

de saúde para

pessoas que usam

drogas no Brasil. O

Ministério da Saúde

apresenta uma

proposta de atenção, influenciada por

duas grandes

experiências:

a Reforma

Psiquiátrica e o

Programa Nacional

de Doenças

Sexualmente

transmissíveis e

Aids (DST/Aids),

especificamente por

meio de projetos de

redução de danos pansão da rede de saúde mental, obedecendo aos princípios da Reforma Psiquiátrica, com vistas a substituir o modelo hospitalocêntrico por redes de atenção especializadas e compostas por dispositivos territoriais 11 .

Porém, concomitantemente as políticas de repressão e proibicionistas atuam também baseadas na mesma Política, enfatizando-se aqui a incongruência já supracitada. Souza e Kantorski16 dizem que com a preconização de tratamentos diferenciados, um que se pretende redutor de danos à saúde e outro que se apresenta baseado em abordagens repressivas, não há lugar para congruências.

Para responder à necessária mudança no modelo proposto pela Reforma Psiquiátrica, a política de saúde mental prevê a construção de uma rede de atenção a usuários de álcool e outras drogas com a implantação e/ou implementação de Centros de Atenção Psicossocial Álcool e outras Drogas, os CAPS AD, que se apresentam estratégicos na organização da rede em seu território de atuação, oferecendo a articulação com os mais variados dispositivos comunitários, sociais e de saúde, com o objetivo de integralizar a atenção e a inclusão social de usuários e seus familiares11. Santos e Oliveira17 complementam que a função principal dos CAPS AD é promover a articulação em rede de serviços nas ações de redução de danos, prevenção, recuperação, tratamento/cuidado e reinserção social das pessoas que usam drogas.

Nesse sentido, a Portaria no 3.088 de 201118, que foi alterada pela Portaria ${ }^{\circ}$ 3.588 de 20174, institui a Rede de Atenção Psicossocial - conhecida como RAPS para pessoas com sofrimento ou transtorno mental e com necessidades recorrentes do uso de drogas, no âmbito do Sistema Único de Saúde-SUS.

A portaria que institui a "nova" Rede de Atenção Psicossocial desenhou este novo modelo de atenção e incluiu os Hospitais Psiquiátricos na rede, fortalecendo, inclusive, a parceria da saúde com as comunidades terapêuticas. Incluiu ainda o hospital-dia em hospitais psiquiátricos, porém, veda a ampliação dos leitos, com a alegação de reafirmar o modelo assistencial de base co- 


\section{artigo}

Pinheiro, V. A., Mendonça, E. M., Costa, E. C., Calisto, G. C. O., Rodrigues, J. A. R., Lima, B. A. P.

Redução de danos e políticas sobre drogas no Brasil: retrocessos e avanços

munitária

Mas de modo contraditório, o financiamento para as diárias dos hospitais psiquiátricos é reajustado. A "nova rede" continua com alegações sobre a importância da desinstitucionalização, contudo, reforça as instituições que internam os usuários e os mantem por longos períodos distantes da convivência social e comunitária.

Desde o ano de 2020 a vida encontra-se marcada pela pandemia da COVID-19, e fica clara a relevância de abordar a questão da descontinuidade das políticas públicas e de Estado, bem como a influência no cotidiano das populações, principalmente as pessoas vulneradas, que se encontram em situação de rua, em cenas de uso de drogas e encarceradas em seu sentido genérico.

No que diz respeito às pessoas supracitadas, no dia 14 de maio de 2020, de forma verticalizada e sem ampla divulgação, foi publicada a Portaria n ${ }^{\circ} 6919$, da Secretaria Nacional de Assistência Social, do Ministério da Cidadania, aprovando "recomendações gerais para a garantia de proteção social à população em situação de rua, inclusive imigrantes, no contexto da pandemia de Covid-19". O ponto 3.1 traz a articulação com as comunidades terapêuticas previstas no Sistema Nacional de Políticas Públicas sobre Drogas.

Rubens e Martins ${ }^{20}$ descrevem que no dia 24 de julho de 2020, o Diário Oficial da União publica a Resolução $\mathrm{n}^{\circ} 03 \mathrm{de}$ 202021, do Conselho Nacional de Políticas Sobre Drogas-CONAD, órgão vinculado ao Ministério da Justiça e Segurança Pública. A citada resolução descreve linhas para a internação de adolescentes em suposto uso problemático de drogas, em comunidades terapêuticas. Mais um retrocesso, visto que estas pressupõem o asilamento e a manicomialização. Destaca-se ainda, que uma resolução, necessita manter obediência à lei, respeitar marcos regulatórios históricos, conquistados a despeito de lutas indescritíveis, como as Leis 8.08022, 8.06923, 10.2163, e a Portaria n 308818 .

\section{REDUÇÃO DE DANOS}

Historicamente, encontramos que a re-

dução de danos tem suas origens na década de 1920, no Condado de Rolleston, Inglaterra. Os profissionais médicos e enfermeiros, que atuavam em um centro de saúde, ao irem para o trabalho passavam obriga-

No Brasil, devido a questões de saúde, que exigiam novas ações, a redução de danos tem seu início na década de 1980 , a partir do avanço da aids, com a preocupação da contaminação por meio do uso de drogas injetáveis

toriamente por um grupo de moradores de rua, usuários de álcool e heroína injetável. Esses profissionais, então, com o intuito de se aproximar de tais moradores, resolveram distribuir álcool e heroína no centro de saúde. Chegando ao local, os moradores de rua recebiam a porção da droga e, além disso, o direito de tomar banho e lavar suas roupas. Se desejassem, conversavam com os profis- sionais de saúde. A questão primordial era atrair estas pessoas para que surgissem possibilidades de cuidado24. Ainda na mesma década, preocupados com graves questões de saúde que se impunham na Holanda, usuários de drogas injetáveis demandaram do governo que disponibilizasse serviços com vistas a diminuir os riscos de contaminação da hepatite B e pelo vírus HIV. Neste sentido, a redução de danos surge como estratégia viável 25.

No Brasil, devido a questões de saúde, que exigiam novas ações, a redução de danos tem seu início na década de 1980, a partir do avanço da aids, com a preocupação da contaminação por meio do uso de drogas injetáveis. Com isso, a primeira ação emblemática neste aspecto aconteceu em Santos/ SP, e se baseou no fornecimento e troca de seringas26. Tais ações foram interrompidas com alegações de apologia ao uso de drogas. Reforçando com isso, o viés autoritário, que os limitavam o exercer da cidadania27.

No ano de 1995 foi criado o primeiro programa de troca de seringas, em Salvador, Bahia, realmente efetivo no Brasil e na América Latina, sob pressão e julgo, sofrendo ainda resistência de setores sociais, que concebiam a troca de seringas como ilegal e apologia ao uso de drogas 28.

Petuco29 assinala que as práticas de redução de danos provocaram uma profunda ampliação na atuação com pessoas que usam drogas, nas vivências profissionais e nos planos teórico e conceitual, permitindo acompanhar in loco as situações de risco e/ ou vulnerabilidade social associado ao uso de drogas.

Assim, a redução de danos é uma perspectiva que propõe a reflexão de como o usuário se relaciona com as drogas e qual o lugar que a mesma ocupa em sua vida. A oferta de cuidado deve ser de fato uma porta aberta, ofertando serviços a todos, inclusive para os que não querem ou não conseguem interromper o uso das drogas. Com isso, é possível evitar a exposição às situações de risco e potencializa-se uma aproximação com as instituições, possibilitando um pedido de ajuda posterior, se for o caso 25.

Portanto, a redução de danos postula 
intervenções singulares que envolvem o uso protegido, a diminuição do uso, a substituição por substâncias que causem menos impasses, e também a abstinência das drogas que criam problemas aos usuários. Para isso, suas ações possibilitam a aproximação com o usuário, no local onde se encontram: ruas, bares, locais de venda e consumo, pontos de prostituição e comunidades onde residem. Oferecendo uma escuta acolhedora e diferenciada e ainda cuidados de saúde física e psíquica, orientação, insumos de prevenção e encaminhamentos responsáveis para a rede intersetorial formal e informal26.

Faz-se necessário o estímulo à elaboração de estratégias de promoção à saúde às pessoas que usam drogas, com vistas à diminuição das barreiras de acesso ao cuidado.
Inclusive, intervenções de cunho proibicionista podem silenciar as pessoas e com isso, desencorajá-las de buscar apoio30.

\section{CONCLUSÃO}

As políticas sobre drogas no Brasil passaram, nos últimos anos, por uma intensificação das práticas repressivas, mesmo com a permanência da redução de danos na política de drogas por mais de uma década. $\mathrm{O}$ retorno do viés proibicionista provocou um impacto na realidade das políticas públicas no país e nas vivências das pessoas que usam drogas.

Concluiu-se que o predomínio do proibicionismo e seu retorno à legislação dos últimos anos, legitimou oficialmente a cri- minalização do uso de substâncias psicoativas e consequentes retrocessos em relação ao cuidado das pessoas que usam drogas. $\mathrm{O}$ paradigma de combate às drogas passa a ser apoiado e adotado por boa parte dos cidadãos, sendo o tráfico considerado como mais grave e o uso de drogas interpretado como doença, que necessita de tratamento, seja qual for o padrão de uso.

Apesar do exposto, ainda existem possibilidades de construções acerca das políticas sobre drogas no Brasil e no entendimento do tratamento em liberdade, contrário aos modelos manicomiais apresentados como saídas milagrosas, constituindo-se, aliás, importante desafio.

\section{REFERÊNCIAS}

1 Brasil. Resolução n 3, de 27 de outubro de 2005. Dispõe sobre a Política Nacional sobre Drogas [internet]. Brasilia: Conselho Nacional de Políticas sobre Drogas (CONAD), 2005. [acesso em 2021 jul 9]. Disponivel em: https:/www.justica.gov.br/central-de-conteudo/ politicas-sobre-drogas/cartilhas-politicas-sobre-drogas/2011legislacaopoliticaspublicas.pdf

2 Brasil. Nota Técnica $n^{\circ} 11$, de 04 de fevereiro de 2019. Dispõe sobre os esclarecimentos sobre as mudanças na Política Nacional de Saúde Mental e nas Diretrizes da Política Nacional sobre Drogas [internet]. Brasília: Ministério da Saúde, 2019. [acesso em 2021 jul 10]. Disponivel em: http://pbpd.org.br/wp-content/uploads/2019/02/0656ad6e.pdf.

3 Brasil. Lei n 10.216, 06 de abril de 2001. Dispõe sobre a proteção e os direitos das pessoas portadoras de transtornos mentais e redireciona o modelo assistencial em saúde mental [internet]. Brasília: Presidência da República, 2001. [acesso em 2020 dez 12]. Disponivel em: http://www.planalto.gov.br/ccivil_03/leis/leis_2001/ |10216.htm.

4 Brasil. Portaria $n^{\circ} 3.588$, de 21 de dezembro de 2017. Dispõe sobre a Rede de Atenção Psicossocial, e dá outras providências [internet]. Brasilia: Presidência da República, 2017. [acesso 2021 jul 13]. Disponivel em: http://bvsms.saude.gov.br/bvs/saudelegis/gm/2017/ prt3588_22_12_2017.html.

5 Lopes 0 J. Proibicionismo e atenção em saúde a usuários de drogas: tensões e desafios às políticas públicas. Psicol. Soc. 31, e188088, 2019. [acesso em 202127 out]. Disponivel em: https://doi. org/10.1590/1807-0310/2019v31188088.

6 Brasil. Política do Ministério da Saúde para a atenção integral a usuários de álcool e outras drogas [internet]. Brasilia: Ministério da Saúde, 2003. [acesso em 2021 jul 12]. Disponivel em: http://bvsms. saude.gov.br/bvs/publicacoes/pns_alcool_drogas.pdf.

7 Brasil. Lei n 11.343, 23 de agosto de 2006. Institui o Sistema Nacional de Políticas Públicas sobre Drogas - Sisnad [internet]. Brasília: Presidência da República, Secretaria-Geral, Subchefia para Assuntos
Jurídicos, 2006. [acesso 2021 jul 10]. Disponivel em: http://www. planalto.gov.br/ccivil_03/_ato2004-2006/2006/lei/l11343.htm.

8 Brasil. Guia Estratégico para o Cuidado de Pessoas com Necessidades Relacionadas ao Consumo de Álcool e Outras Drogas: Guia AD. Brasília: Ministério da Saúde, 2015.

9 Brasil. Decreto n 9761, de 11 de abril de 2019. Aprova a Política Nacional sobre Drogas [internet]. Brasilia: Presidência da República, 2019. [acesso 2021 jul 19]. Disponivel em: http://www.planalto.gov. br/ccivil_03/_ato2019-2022/2019/decreto/D9761.htm.

10 Brasil. Lei $n^{\circ} 13.840$, de 05 de junho de 2019. Dispõe sobre o Sistema Nacional de Políticas Públicas sobre Drogas [internet]. Brasília: Presidência da República, 2019. [acesso em 2021 jul 12]. Disponivel em: http:/www.planalto.gov.br/ccivil_03/_Ato20192022/2019/Lei/L13840.htm.

11 Alves V.S. (2009). Modelos de atenção à saúde de usuários de álcool e outras drogas: discursos políticos, saberes e práticas [internet]. Cad Saúde Púb. 2009; 25 (11), p. 2309-2319. [acesso em 2020 ago 17]. Disponivel em: https://www.scielo.br/scielo.php?script=sci_arttext\&pid=S0102-311X2009001100002.

12 Castro L. A Redução de Danos à luz do materialismo histórico. [dissertação] [Internet]. Maringá: Universidade Estadual de Maringá; 2018. [acesso em 2020 nov 10]. Disponivel em: http://www.ppi.uem. br/arquivos-2019/lais-castro-dissertacao.

13 Brasil. Departamento Penitenciário Nacional. Levantamento Nacional de Informações de Penitenciárias: período de julho a dezembro de 2019. [acesso em: 25 set 2020]. Disponivel em: https://www. gov.br/depen/pt-br/sisdepe.

14 Teixeira M B, Lacerda A, Ribeiro J M. Potencialidades e desafios de uma política pública intersetorial em drogas: o Programa "De Braços Abertos" de São Paulo, Brasil. Physis: Revista de Saúde Coletiva, Rio de Janeiro, v. 28(3), e280306, 2018. [acesso 19 out 2021]. DOI: http://dx.doi.org/10.1590/S0103-73312018280306. 


\section{artigo}

Pinheiro, V. A., Mendonça, E. M., Costa, E. C., Calisto, G. C. O., Rodrigues, J. A. R., Lima, B. A. P.

Redução de danos e políticas sobre drogas no Brasil: retrocessos e avanços

\section{REFERÊNCIAS}

15 Machado A R. Uso Prejudicial de Álcool e outras Drogas como Sofrimento Mental: a lógica de cuidado no SUS. In: Escola de Saúde Pública de Minas Gerais/MG (Org.), trabalho apresentado no I Seminário de Saúde Mental, em Belo Horizonte - MG: Escola de Saúde Pública/MG, 2011.

16 Souza J, Kantorski L P. A rede social de indivíduos sob tratamento em um CAPS ad: o ecomapa como recurso. Rev Esc Enfermagem USP. 2009; 43(2), p. 373-83. [acesso em 2021 set 8]. Disponivel em: https://www.scielo.br/pdf/reeusp/v43n2/a17v43n2.pdf.

17 Santos J AT, Oliveira M L F. Políticas públicas sobre álcool e outras drogas: breve resgate histórico. Saúde \& Transformação Social/ Health \& Social Change. 2013; 4 (1), p. 82-89.

18 Brasil. Portaria $n^{\circ} 3.088$, de 23 de dezembro de 2011. Dispõe sobre a Rede de Atenção Psicossocial para pessoas com sofrimento ou transtorno mental e com necessidades decorrentes do uso de crack, álcool e outras drogas, no âmbito do Sistema Único de Saúde. Brasília: Ministério da Saúde. [acesso em 2020 nov 10]. Disponivel em: http://bvsms.saude.gov.br/bvs/saudelegis/gm/2011/ prt3088_23_12_2011_rep.html.

19 Brasil. Portaria $n^{\circ}$ 69, de 14 de maio de 2020. Aprova recomendações gerais para a garantia de proteção social à população em situação de rua, inclusive imigrantes, no contexto da pandemia do novo Coronavírus, Covid-19. Brasília: Diário Oficial da União, 18 de maio de 2020, p. 379, 2020. [acesso 2021 jul 15]. Disponivel em: https://www.in.gov.br/en/web/dou/-/portaria-n-69de-14-de-maio-de-2020-257197675.

20 Rubens C, Martins F. (2020). Breves anotações sobre a Resolução 03/20 do CONAD. Site Ministério Público do Mato Grosso. Cuiabá: Publicado em 24 de agosto de 2020. [acesso em 2020 nov 15]. Disponivel em:https://mpmt.mp.br/conteudo/58/88960/sobre-a-resolucao-0320-do-conad.

21 Brasil. Resolução n 3, de 24 de julho de 2020. Regulamenta, no âmbito do Sistema Nacional de Políticas Públicas sobre Drogas - Sisnad, o acolhimento de adolescentes com problemas decorrentes do uso, abuso ou dependência do álcool e outras drogas em comunidades terapêuticas. Brasília: Sistema Nacional de Políticas Públicas sobre Drogas, 2020. [acesso em 2021 out 10]. Disponivel em: https:// crianca.mppr.mp.br/2020/07/333/LEGISLACAO-CONAD-regulamenta-o-acolhimento-de-adolescentes-em-comunidades-terapeuticas.html\#: :text=Foi $\% 20$ publicada $\% 2$ C 20 no $\% 20$ dia $\% 2028 \% 20$ \%C3\%BAltimo $\% 2$ C $\% 20$ no $\% 20$ Di $\%$ C $3 \%$ A 1 rio,do $\% 20 \%$ C $3 \%$ A 1 lcool $\% 20$ e\%20outras $\% 20$ drogas $\% 20$ em $\% 20$ comunidades $\% 20$ terap $\%$ C3\%AAuticas.
22 Brasil. Lei $n^{\circ}$ 8.080, de 19 de setembro de 1990. Dispõe sobre as condições para a promoção, proteção e recuperação da saúde, a organização e o funcionamento dos serviços correspondentes e dá outras providências. Brasília: Presidência da República, 2020. [acesso em 2021 jul 15]. Disponivel em: http://www.planalto.gov.br/ccivil_03/leis/l8080.htm.

23 Brasil. Lei n 8.069, de 13 de julho de 1990. Dispõe sobre o Estatuto da Criança e do Adolescente e dá outras providências. Brasilia: Presidência da República, 2013. [acesso em 2021 jul 15]. Disponível em: http://www.planalto.gov.br/ccivil_03/leis//8069.htm.

24 Siqueira D. A política de redução de danos no Brasil e os direitos fundamentais do homem. In: Caminhos do Cuidado: caderno do tutor. Brasília: Ministério da Saúde, 2013, p. 84-91.

25 Cruz M S. Prevenção do uso de drogas: capacitação para conselheiros e lideranças comunitárias. Brasilia: Ministério da Justiça Secretaria Nacional de Políticas sobre Drogas (SENAD), 2013.

26 Siqueira D, Lindner L. Redução de Danos: como foi? 0 que é possivel? 0 que é preciso? In: Souza A C et al. Entre pedras e fissuras: a construção da atenção psicossocial de usuários de drogas no Brasil. São Paulo: Hucitec Editora; 2016.

27 Passos E H, Souza T P. Redução de danos e saúde pública: construções alternativas à política global de "Guerra às Drogas". Ver. Psic. e Soc. 2011; 23 (1), p.154-162. [acesso 2020 nov 13]. Disponivel em: https://www.scielo.br/scielo.php?pid=\$010271822011 000100017\&script=sci_abstract\&tIng=pt.

28 Andrade T M. Reflexões sobre políticas de drogas no Brasil. Ciência \& Saúde Col, 201116 (12), p. 4665-4674. https://www.scielo.br/ scielo.php?script=sci_abstract\&pid=S1413-81232011001300015 \&tlng=pt.

29 Petuco D R S. Era uma vez: uma pequena história do cuidado e das políticas públicas dirigidas a pessoas que usam álcool e outras drogas. In: Teixeira M, Fonseca Z (Orgs.). Saberes e práticas na atenção primária à saúde: cuidado à população em situação de rua e usuários de álcool, crack e outras drogas. São Paulo: Hucitec; 2015, p. $179-200$

30 Francelino, G G, Quinderá P H D, Rimes T S, Andrade A T, Costa $L S P$, Morais S F. Compreensões de estudantes e professores de uma escola pública de ensino fundamental sobre uso de crack na adolescência. DOI: https://doi.org/10.36489/saudecoletiva.2021v11i62p5038-5049. Saúde Coletiva - 2021; (11) N.62, p. 5038-5043. 